\title{
Components Associated With Saltiness Potentiation in Frankfurters Made With Traditionally Brewed Soy Sauce
}

\author{
Elizabeth M. Price ${ }^{1}$, Scott A. Rankin², Taro Horiba ${ }^{3}$, MaryAnne A. Drake ${ }^{4}$, and Jeffrey J. Sindelar ${ }^{1 *}$ \\ ${ }^{1}$ Meat Science \& Muscle Biology Laboratory, Department of Animal Sciences, University of Wisconsin, Madison, \\ WI 53706, USA \\ ${ }^{2}$ Department of Food Science, University of Wisconsin, Madison, WI 53706, USA \\ ${ }^{3}$ Kikkoman USA R\&D Laboratory, Inc., Madison, WI 53719, USA \\ ${ }^{4}$ Department of Food, Bioprocessing \& Nutrition Science, North Carolina State University, Raleigh, NC 27695, USA \\ *Corresponding author. Email: jsindelar@wisc.edu (Jeffrey J. Sindelar)
}

\begin{abstract}
Salt is a critical ingredient in processed meat and poultry products because of its multiple functions that affect product quality and safety. Although salt is a functional ingredient in food products, sodium reduction continues to be an important topic within the food industry due to interests in reducing dietary sodium intake. Previous work has shown that soy sauce addition may potentiate saltiness perception in processed meats and thus allow for novel formulations with reduced sodium content. Two studies were conducted to further elucidate these effects. First, trained panel sensory characteristics, relevant quality parameters, and selected chemical profiles were determined comparing frankfurters containing flake salt and traditionally brewed soy sauce. Seven aqueous compounds were found to be more abundant $(P<0.001)$ in the soy sauce-containing treatment, and 56 volatile compounds were identified. Principal component analysis of the sensory and selected chemical profiles led to the consideration that ethyl hexanoate (EHEX) may be a causative agent of the saltiness-potentiating phenomenon. Thus, a second study further evaluated concentrations of EHEX, revealing that trained sensory panelists perceived frankfurters containing EHEX as saltier $(P<0.05)$ and these frankfurters had higher scores for fermented/sour aromatic score $(P<0.05)$ than the control (Control: $100 \% \mathrm{NaCl}$ from flake salt). This research demonstrated the ability of EHEX to potentiate saltiness in frankfurters with minimal effects on quality.
\end{abstract}

Key words: frankfurters, soy sauce, ethyl hexanoate, saltiness, potentiation

Meat and Muscle Biology 5(1): 9, 1-16 (2021) doi:10.22175/mmb.11476

Submitted 24 June $2020 \quad$ Accepted 13 September 2020

\section{Introduction}

Key reasons for the addition of salt in foods include its ability to modify or enhance flavors, serve as a preservative from microbial and chemical spoilage, and contribute to textural and functional characteristics (Hutton, 2002). In meat products, salt increases water-holding capacity, improves protein extraction and binding, provides flavor, and is often included at levels sufficient for bacteriostatic function (Desmond, 2006). A salt concentration of $2.0 \%-2.5 \%$ is typical in the manufacture of a commercial frankfurter (Sofos, 1983).
Sodium is an essential nutrient for humans for proper cellular function, to maintain a balance between water and minerals in the body, to assist with nerve and muscle function, and to aid in nutrient absorption (Tarver, 2010). However, excess sodium can cause high blood pressure and increased risk of cardiovascular disease (WHO, 2016). The recommended maximum for sodium intake by adults in the United States is $2,300 \mathrm{mg} / \mathrm{d}$ (U.S. Department of Health and Human Services and USDA, 2015). The average for sodium intake by adult men and women in the US is $4,240 \mathrm{mg} / \mathrm{d}$ and $2,980 \mathrm{mg} / \mathrm{d}$, respectively; a majority of sodium intake comes from 
processed or prepared foods (U.S. Department of Health and Human Services and USDA, 2015). The food industry has employed multiple strategies to reduce and replace sodium in food products, with one method being a step-down approach to reduce salt over time (Kuhn, 2010; Tarver, 2010). Another option is to replace salts containing sodium with non-sodium ingredients that provide a salty taste and provide other similar functions. Research is ongoing to find new, novel ingredients and approaches to provide the functionality and flavor of salt (Tarver, 2010). One novel approach to reduce sodium in food products has been through the addition of traditionally brewed soy sauce (SS) due to its saltiness enhancement capability. Kremer et al. (2009), McGough et al. (2012a, 2012b), and Shazer et al. (2017) found that saltiness could be enhanced by SS added to food products.

However, limited research has been conducted to elucidate the chemical basis of SS-induced saltiness potentiation. Previous research identified over 300 compounds in the volatile fraction of SS (Feng et al., 2015). These compounds belong to 14 chemical classes-esters, pyrazines, ketones, furans, alcohols, aldehydes, acids, sulfur containing compounds, phenols, lactones, furnanones, pyrenes, hydrocarbons, and acetals — of which alcohols, acids, aldehydes, and esters are the most abundant (Luh, 1995; Feng et al., 2015). To complement a more thorough understanding of the chemical profiles of SS, sensory responses could link the saltiness response with a compound or group of compounds responsible for saltiness, thus leading to an ability to develop and enhance broader sodium-reduction applications.

It is hypothesized that specific saltiness-potentiating compounds developed by the addition of SS to frankfurters reside in either the aqueous fraction or the volatile fractions. Thus, the objectives of this study were to (1) generate complementary sensory and chemical profile data with SS-containing frankfurters, (2) use these data to identify compound(s) associated with or potentially responsible for saltiness, and (3) confirm the saltiness-potentiating effects of compounds identified in Objective 2 through their addition to-and the sensory assessment of-an authentic frankfurter without added SS.

\section{Materials and Methods}

\section{Experimental design and data analysis}

The first and second objectives (referred to as Study 1) included treatments involving 2 frankfurter formulations: one treatment made with $50 \% \mathrm{NaCl}$ from flake salt (FS) and 50\% $\mathrm{NaCl}$ from SS (Treatment) and a control with $100 \% \mathrm{NaCl}$ from FS (Control). Objective 3 included 3 treatments containing increasing concentrations of added ethyl hexanoate (EHEX; 10, 20, and $50 \mu \mathrm{g} / \mathrm{kg}$ ) and a Control with no added EHEX (referred to as Study 2). Treatments for all study objectives were repeated in triplicate. As a means of further confirmation, the Objective 3 experiment was repeated in its entirety twice. These experimental designs enabled one-way ANOVA analyses for all variables. Statistical analysis was performed for all measurements using JMP statistical software (SAS, JMP Pro version 13.1.0; SAS Institute Inc., Cary, NC). For Objective 2, principal component analyses (PCA) were conducted to establish potential associations between the sensory attributes and chemical profiles. Significance levels were determined with $\alpha<0.05$.

\section{Product manufacture}

Ready-to-eat, emulsified frankfurters were manufactured using $90 \%$ lean beef and $42 \%$ lean pork trimmings sourced from a local supplier (UW Provision, Middleton, WI). Proximate analysis was conducted for the raw materials to adjust the formulation targeting a 30\% fat finished frankfurter. Trimmings were randomly separated into batches, vacuum packaged and randomly assigned to a treatment or control and stored under refrigeration $\left(4^{\circ} \mathrm{C}\right)$ until product manufacture (1 to $3 \mathrm{~d})$.

Emulsions for both studies were produced using methods described by Rust (1987). Emulsified frankfurters (Table 1) were manufactured using a bowl chopper (Krämer \& Grebe 67-225, Krämer \& Grebe GmbH \& Co. KG, Biendenkopf-Wallau, Germany). Ice was chopped to cool the bowl cutter and discarded before beginning manufacture. Coarse ground beef, sodium nitrite, FS, SS (if included in formula), and ice were chopped until reaching $2.2^{\circ} \mathrm{C}$. Prior to addition, SS was heated in a water bath at $75^{\circ} \mathrm{C}$ for $7 \mathrm{~h}$ to deactivate SS proteases as done in previous studies (McGough et al., 2012a, 2012b; Shazer et al., 2017) and was added along with the coarse ground pork, spices, sodium phosphates, and sodium erythorbate and chopped until reaching $14.4^{\circ} \mathrm{C}$. The emulsion was then stuffed into $80-\mathrm{g}$ portions using $27-\mathrm{mm}$ cellulose casings (ViskoTeepak USA, Kenosha, WI) followed by submerging in a liquid smoke solution for $1 \mathrm{~min}$ and 45 $\mathrm{s}$ prior to thermal processing. The dilution of liquid smoke was made by combining 35\% liquid smoke (RA1505, Red Arrow, Manitowoc, WI) with 65\% water. The Treatments and Control were placed on 
Table 1. Frankfurter formulations for frankfurter Treatments and a Control used in Studies 1 and 2

\begin{tabular}{lcccc}
\hline \hline & \multicolumn{2}{c}{ Study 1*:FS Replacement Using SS } & \multicolumn{2}{c}{ Study 2*:Addition of EHEX to Frankfurters } \\
\cline { 2 - 4 } & C (\%) & TRT (\%) & Replication 1 (\%) & Replication 2 (\%) \\
\hline 90\% Lean Beef Trim & 47.74 & 47.74 & 51.66 & 69.34 \\
$\mathbf{5 0 \% ~ L e a n ~ P o r k ~ T r i m ~}$ & 52.26 & 52.26 & 25.00 & 30.69 \\
Water (Ice) & 25.00 & 17.13 & 2.50 & 25.00 \\
FS & 2.50 & 1.25 & - & 2.50 \\
SS & 0.00 & 9.12 & 1.67 & - \\
Spices & 1.67 & 1.67 & 0.50 & 1.67 \\
Sodium Tripolyphosphates & 0.50 & 0.50 & 0.05 & 0.50 \\
Sodium Erythorbate & 0.05 & 0.05 & 0.25 & 0.05 \\
Curing Salt (6.25\% Nitrite) & 0.25 & 0.25 & 0.25 \\
\hline
\end{tabular}

*Study $1 \mathrm{C}$ batch size $=19.86 \mathrm{~kg}$; Study $1 \mathrm{SS}$ batch size $=19.02 \mathrm{~kg}$; Study 2 replication 1 batch size $=15.92 \mathrm{~kg}$; Study 2 replication 2 batch size $=18.86 \mathrm{~kg}$.

C, Control; EHEX, ethyl hexanoate; FS, flake salt; SS, soy sauce; TRT, Treatment.

smokehouse sticks, then onto a smokehouse truck. A single smokehouse truck was used for thermal processing (Alkar Model 450 MiniSmoker, Alkar Engineering Corp., Lodi, WI) with a standard frankfurter smokehouse schedule cooking to an internal temperature of $71.1^{\circ} \mathrm{C}$. Immediately after thermal processing, the frankfurters were chilled in a cooler $\left(3^{\circ} \mathrm{C}\right)$ until reaching an internal temperature below $4.4^{\circ} \mathrm{C}$. After cooling, frankfurters were removed from the cellulose casings, placed into packages, and then vacuum sealed (Flavorseal Vacuum Pouch, 3 mil Carroll Manufacturing and Sales, Avon, $\mathrm{OH} ; \mathrm{O}_{2}$ transmission rate: $52 \mathrm{cc} / \mathrm{m}^{2}$ per 24 h) (Ultravac 2100-C Vacuum Packager, Koch Equipment, Kansas City, MO; seal setting $=5$, vacuum setting =5). Samples for Study 1 physicochemical and sensory evaluation were stored at $2{ }^{\circ} \mathrm{C}$ until further analysis was conducted. Extraction samples were stored at $-20^{\circ} \mathrm{C}$ to minimize chemical changes during storage. Study 2 samples to be used for sensory evaluation, quantitative color analysis, salt, and $\mathrm{pH}$ measurements were sliced into $2.54-\mathrm{cm}$ pieces and vacuum packaged and stored at $2^{\circ} \mathrm{C}$ until further analysis was conducted.

\section{Ethyl hexanoate preparations (Study 2)}

Food-grade EHEX was obtained (Sigma Aldrich, St. Louis, MO) for all Treatments. Dilutions were made using food-grade ethanol (Sigma Aldrich, St. Louis, $\mathrm{MO}$ ). Frankfurters were sliced into $2.54-\mathrm{cm}$ pieces post manufacture and randomly assigned to a Treatment or Control, then injected via hypodermic needle with target EHEX solutions. Injected samples were vacuum packaged and stored at $4^{\circ} \mathrm{C}$ for a minimum of $5 \mathrm{~d}$ after injection and prior to analysis (day 14) to allow for equilibration as determined by preliminary research (data not shown).

\section{Physicochemical and qualitative analyses}

Proximate analyses (AOAC 2000a, 2000b, 2000c) were conducted in triplicate for moisture and fat (CEM Smart Trac, CEM, Matthews, NC) and for protein analysis (CEM Sprint Rapid Protein Analyzer, CEM, Matthews, NC) for raw materials and finished product, with Objective 2 measurements being conducted on the cooked batch. Instrumental color, or Commission Internationale de l'Eclairage (CIE) $L^{*}$ (lightness), $a^{*}$ (redness), and $b^{*}$ (yellowness) values, were obtained on both the interior and exterior of frankfurters (Minolta Chromameter, Model CR-300, Minolta Camera Co., Ltd., Osaka, Japan; $1 \mathrm{~cm}$ aperture, illuminant $\mathrm{C}, 2^{\circ}$ observer angle) with methods adapted from Sebranek et al. (2001). Frankfurters were sliced lengthwise and immediately placed into vacuum bags and measured at 3 random locations on 3 frankfurters, yielding 9 measurements in total. Measurements were taken $2 \mathrm{wk}$ post manufacture to mimic a representative timeframe for retail availability to consumers. The $\mathrm{pH}$ was measured using methods described by Sebranek et al. (2001). Measurements were taken in duplicate. The amount of purge was measured for all samples by the following equation:

$$
\begin{aligned}
& \text { Percent purge } \\
& \quad=([\text { total weight }- \text { bag weight }- \text { meat weight }] \\
& \quad \div \text { meat weight }) \times 100
\end{aligned}
$$

The stability of the raw emulsion was measured on the day of product manufacture using the Rongey Method (Sebranek et al., 2001). Emulsion stability tests were conducted in duplicate for the Treatments and Control. Liquid separation was calculated by the following equations: 


$$
\begin{gathered}
\% \text { Water Separation }=\frac{\mathrm{mL} \mathrm{Water}}{\text { Sample Weight }} * 100 \\
\begin{aligned}
\% \text { Fat Separation }= & \frac{\mathrm{mL} \mathrm{Fat}}{\text { Sample Weight }} * 100 \\
\% \text { Total Liquid Separation }= & \% \text { Water Separation } \\
& +\% \text { Fat Separation }
\end{aligned}
\end{gathered}
$$

Cook yield was measured for the entire batch of frankfurters by weighing the total raw batch prior to thermal processing and reweighing the total batch after thermal processing and complete cooling. Cook yield was calculated by the following equation:

$$
\text { Cook Yield }=(\text { Cooled Weight } \div \text { Raw Weight }) \times 100
$$

The percent salt in the frankfurters was measured using the method by Sebranek et al. (2001). Chloride titration test strips (Quantab Titrators for Chloride, High Range Titrators; 300-6,000 mg/kg Cl; Hach Company, Loveland, $\mathrm{CO}$ ) were used to measure the salt in the solution, and measurements were done in duplicate for each treatment. Texture profile analysis was conducted using methods described by Wenther (2003) and Bourne (1978). A 25-mm-diameter cylinder (TA25) was attached to the TA-HD-Plus Texture Analyzer (Texture Technologies Corp., South Hamilton, MA) to analyze the textural profile of the samples (injected samples for Study 2). Calibration was done by using a $5-\mathrm{kg}$ weight, a height set to $30 \mathrm{~mm}$, and Texture Expert software (version 6.1.4.0). A two-compression test was conducted on cored $(1.6 \mathrm{~cm}$ diameter, $1.9 \mathrm{~cm}$ length) chilled frankfurter samples. Two compression cycles were tested, two-cycle $50 \%$ and two-cycle $72 \%$. Pretest speed was $2.0 \mathrm{~mm} / \mathrm{s}$, test speed was $3.3 \mathrm{~mm} / \mathrm{s}$, and post-test speed was $5.0 \mathrm{~mm} / \mathrm{s}$ with a 3 -s delay between compressions. One measurement was taken per core, and 2 cores were taken from 4 links (Study 1) or 8 injected pieces (Study 2) of both the Treatments and Control, resulting in 16 total measurements, 8 per two-cycle compression. Texture analysis was conducted $2 \mathrm{wk}$ post manufacture and 1 wk post injection.

Puncture analysis was conducted using methods described by Wenther (2003). A 2-mm-diameter cylindrical probe (TA-52) was attached to the TA-HD-Plus Texture Analyzer (Texture Technologies Corp., South Hamilton, MA) to analyze the textural profile of the samples. The 2-mm probe was programmed to penetrate 12 $\mathrm{mm}$ into the sample after $12 \mathrm{~g}$ of surface resistance was detected by the TA-HD-Plus. The pretest speed was $3.0 \mathrm{~mm} / \mathrm{s}$, the penetration speed was $1.5 \mathrm{~mm} / \mathrm{s}$, and the post-test speed was $10.0 \mathrm{~mm} / \mathrm{s}$. Samples were removed from refrigeration $1 \mathrm{~h}$ prior to analysis for uniform sampling.

Penetration peak force (puncture) was measured for each sample. The peak force was the maximum force required to break the skin of the sample. Two samples were measured, with 4 measurements per sample, yielding 8 total measurements, and 8 pieces were measured for each Treatment and Control in Study 1. Puncture analysis was conducted 2 wk post manufacture and $1 \mathrm{wk}$ post injection.

\section{Trained sensory panel analysis}

Sensory evaluation was conducted using a trained sensory panel. An Institutional Review Board protocol for sensory analysis of SS was filed and approved by North Carolina State University Institutional Review Board prior to initiation of study. All 7 panelists had at least $150 \mathrm{~h}$ of previous experience in sensory analysis of food flavors and aromas using the Spectrum ${ }^{\mathrm{TM}}$ descriptive analysis method (Meilgaard et al., 2007) prior to evaluation. Additional calibrations for frankfurter flavor and texture were conducted utilizing one 2-h training session. Calibration sessions included commercial products and authentic test samples from the study. Panelists were provided with basic taste solutions of known intensities (Spectrum basic taste references) and both commercial frankfurters with intensities established during training as references during evaluation. Sensory evaluation was conducted 2 wk post manufacture, and each sample was evaluated in triplicate. The attributes to be evaluated were selected to represent the spectrum of samples evaluated. The attributes evaluated were smoke, meaty, fruity-fermented, salt, umami, bitter, metallic, fermented/sour aromatic, astringent, hardness, and crosswise hardness using a 15-point scale. For evaluation, the samples were placed in boiling water for 5-6 min, then removed for sample evaluation. Frankfurter pieces ( $2.54 \mathrm{~mm}$ long) were randomly presented to panelists with randomly assigned 3-digit codes in covered sample cups.

\section{Aqueous and volatile fraction extraction and analysis}

Aqueous fractions were extracted using methods described by Richards et al. (2002). A food processor (KitchenAid, KFC 3516ER, Bentor Harbor, MI) was used to create a slurry by combining frankfurters $1: 1$ with distilled, deionized water, then dispersing the resulting slurry into polycarbonate $250-\mathrm{mL}$ centrifuge bottles. Samples were centrifuged at $13,545 \times g$ force for $1 \mathrm{~h}$ at $4^{\circ} \mathrm{C}$ (Avanti J-E with rotor JLA-16.250, 
Beckman Coulter, Brea, CA). The aqueous fraction was separated from the pellet by filtration (Whatman Number 1 paper), and the liquid fraction was filtered again using a 3-kDa filter to remove high-molecularweight compounds. Filtered samples were stored at $-20^{\circ} \mathrm{C}$ until needed.

High-pressure liquid chromatography and a mass spectrometer (MS) were used to analyze the aqueous fraction using a method adapted from $\mathrm{Qu}$ et al. (2016) (an AB Sciex TOF/TOF 4800 MALDI instrument, AB Sciex, Foster City, CA). Solvent A was $0.1 \%$ formic acid in water, and solvent $B$ was $0.1 \%$ formic acid in acetonitrile with a reverse phase column (Agilent Stablebond C18, $2.0 \mathrm{~mm} \times 50 \mathrm{~mm}$ with 1.8 $\mu \mathrm{m}$ particle size; Agilent Technologies Inc., Palo Alto, CA). The flow rate was $250 \mu \mathrm{L} / \mathrm{min}$, and the column was set to $35^{\circ} \mathrm{C}$. The initial solvent composition was $2.0 \% \mathrm{~B}$ for $2 \mathrm{~min}$, increased to $40 \% \mathrm{~B}$ at 27 min, increased to $95 \% \mathrm{~B}$ at $30 \mathrm{~min}$, and decreased to $2.0 \% \mathrm{~B}$ at $32 \mathrm{~min}$, then held until $45 \mathrm{~min}$. Mass spectra data were collected in the $\mathrm{m} / \mathrm{z}$ range of $50-3,200$ with 10,000 transients collected per scan $(0.89 \mathrm{scans} / \mathrm{s})$. The electrospray voltage was 3,700 , and the fragmentor was $140 \mathrm{~V}$. The aqueous extracts were analyzed in triplicate. Tentative compound identification was conducted by matching the compound mass using the Metlin metabolite database (https://metlin.scripps.edu/index. php) by Scripps Center for Metabolomics (La Jolla, CA). Compounds were selected for evaluation based on whether they were 50 times more abundant than the Control sample with a minimum relative abundance greater than 10,000 .

Frankfurters were analyzed for their volatile composition using solid-phase microextraction using a method adapted from Leksrisompong et al. (2010). A 50/30 $\mu \mathrm{m}$ divinylbenzene/Carboxen/polydimethylsiloxane (StableFlex, Supelco, Sigma Aldrich, St. Louis, MO) fiber was exposed to a vial containing $2 \mathrm{~g}$ of sample and held at $40^{\circ} \mathrm{C}$ for $25 \mathrm{~min}$ in $10-\mathrm{mL}$ headspace vials (Restek Corporation, Bellefonte, PA). After exposure, the fiber was analyzed for volatile compounds using gas chromatography (GC) with MS detection. The GC (Agilent 6890N, Agilent Technologies Inc., Palo Alto, CA) was paired with a mass selective detector (Agilent 5973 MS, Agilent Technologies Inc.) and fitted with a fused-silica capillary column $(\mathrm{RTx}-5 \mathrm{MS}, 30 \mathrm{~m}$ long $\times 0.025 \mathrm{~mm}$ i.d. $\times$ $0.05 \mu \mathrm{m}$ film thickness; Restek Corporation, Bellefonte, PA). The front inlet initial temperature was $250^{\circ} \mathrm{C}$ with a flow of $40 \mathrm{~mL} / \mathrm{min}$, using helium as the carrier gas. The sample injection mode was set to splitless, and the oven temperature began at $30^{\circ} \mathrm{C}$ and was set to increase at a rate of $8^{\circ} \mathrm{C} / \mathrm{min}$ until reaching $250^{\circ} \mathrm{C}$, the final temperature. Two analyses were conducted per sample, with 3 samples total, yielding 6 measurements. Chemstation Software (Rev. D.02.00 SP1, Agilent Technologies Inc.) was used to analyze the compounds for tentative identification. Compounds tentatively identified using GC-MS were then positively identified using known standards (Sigma Aldrich, St. Louis, MO).

\section{Results and Discussion}

\section{Physicochemical and qualitative analyses: Study 1}

Although there were no differences between the Treatment and Control for external $L^{*}$ values, external $a^{*}$ values were lower in the Treatment compared to Control, and the $b^{*}$ values were higher in the Treatment compared to Control (Table 2). We attribute these differences to SS-based pigmentation, and a similar trend was noted for internal CIE color values. We further note that, although the instrumental color assessments had statistical differences between the Treatments and Control, they had minimal visual differences, suggesting little practical impact. The $\mathrm{pH}$ levels, percent purge loss, emulsion stability, cook yield, and percent salt values displayed no treatment effects (Table 2).

Means of instrumental texture measurements (textural profile analysis and puncture measurements) are displayed in Table 2. The Treatment was harder, more chewy, and required less peak force to break through the skin compared to the Control. It is unclear why this was observed but may attributed to differences in the delivery of ingredients impacting emulsification and subsequent gel formation during product manufacture. There were no differences between the Treatment and Control for springiness and cohesiveness. McGough et al. (2012a) observed similar results in frankfurters containing various levels of FS and SS, where hardness and chewiness were affected by the addition of SS, but found no differences for springiness or cohesiveness.

\section{Trained sensory panel analysis: Study 1}

Scores for salty taste were higher in the Treatment than Control (Table 3). This complements previous results in which consumer panels perceived frankfurters to be saltier when $50 \%$ of sodium from FS was replaced with SS compared to a $100 \%$ FS control 
Table 2. Means for Study 1 physicochemical and qualitative analysis for emulsified frankfurters containing traditionally brewed SS containing 50\% $\mathrm{NaCl}$ from $\mathrm{FS}$ and $50 \% \mathrm{NaCl}$ from SS (Treatment) and a control frankfurter containing $100 \% \mathrm{NaCl}$ from FS and no SS (Control)

\begin{tabular}{|c|c|c|c|}
\hline Analysis & $\mathrm{C}^{1}$ & TRT $^{1}$ & $\mathrm{SEM}^{2}$ \\
\hline External $L^{* 3}$ & 59.96 & 59.78 & 0.25 \\
\hline External $a^{* 3}$ & 21.92 & 19.78 & $0.33^{14}$ \\
\hline External $b^{* 3}$ & 14.98 & 15.74 & $0.21^{14}$ \\
\hline Internal $L^{* 3}$ & 68.98 & 66.17 & $0.10^{14}$ \\
\hline Internal $a^{* 3}$ & 15.27 & 15.02 & $0.05^{14}$ \\
\hline Internal $\boldsymbol{b}^{* 3}$ & 8.93 & 12.55 & $0.02^{14}$ \\
\hline $\mathbf{p H}^{4}$ & 6.18 & 6.13 & 0.01 \\
\hline Purge $(\%)^{5}$ & 0.45 & 0.24 & 0.18 \\
\hline Emulsion Stability (\%) & 9.40 & 8.60 & 0.19 \\
\hline Cook Yield $(\%)^{7}$ & 90.70 & 90.97 & - \\
\hline Salt $(\%)^{8}$ & 2.65 & 2.70 & 0.02 \\
\hline Hardness $(\mathbf{N})^{9}$ & 42.76 & 51.32 & $0.91^{14}$ \\
\hline Springiness $(\%)^{10}$ & 77.6 & 77.4 & 4.02 \\
\hline Cohesiveness $(\%)^{11}$ & 59.22 & 61.16 & 1.03 \\
\hline Chewiness $(\mathbf{N} \text { mm })^{12}$ & 18.93 & 22.48 & $0.53^{14}$ \\
\hline Puncture $(\mathbf{N})^{13}$ & 2.27 & 2.11 & $0.04^{14}$ \\
\hline
\end{tabular}

${ }^{1} \mathrm{C}=100 \%$ salt from FS; TRT $=50 \%$ salt from FS, $50 \%$ salt from SS.

${ }^{2} \mathrm{SEM}=$ standard error of the means for physicochemical and qualitative analyses.

${ }^{3}$ Commission Internationale de l'Eclairage (CIE) $L^{*}, a^{*}, b^{*}$, where $L^{*}=$ lightness or darkness on a 0 (black) to 100 (white) scale, $a^{*}=$ redness (positive value) or greenness (negative value), and $b^{*}=$ yellowness (positive value) or blueness (negative value).

${ }^{4} \mathrm{pH}$ of fully cooked emulsified frankfurters.

${ }^{5}$ Percentage of purge in fully cooked emulsified frankfurter product package after 2-wk storage at $4^{\circ} \mathrm{C}$.

${ }^{6}$ Emulsion stability raw emulsion $=$ percentage of total liquid separation, calculated by the summation of percentage of water separation and percentage of total fat separation.

${ }^{7}$ Percentage cook yield $=([$ raw weight of frankfurters $\div$ cooked weight of frankfurters] $\times 100$ ).

${ }^{8}$ Percentage of salt in fully cooked emulsified frankfurters.

${ }^{9}$ Hardness $=$ the peak force during the first compression (compressed $72 \%)$.

${ }^{10}$ Springiness $=$ the percent of height the sample recovered during the time that elapses between the end of the first bite and the start of the second bite (50\% compression).

${ }^{11}$ Cohesiveness $=$ the ratio of the positive force area during the second compression $(50 \%)$ to that during the first compression $(50 \%)$, calculated as $([$ Area $2 \div$ Area 1$] \times 100)$.

${ }^{12}$ Chewiness $=$ the product of $($ hardness $\times[$ cohesiveness $\div 100] \times$ springiness).

${ }^{13}$ Puncture $=$ the peak force required to break the outer surface/skin of the frankfurter.

${ }^{14}$ Indicates mean values in row are significantly different at $\alpha<0.05$.

C, Control; FS, flake salt; SS, soy sauce; TRT, Treatment.
(McGough et al., 2012a). Replacing 50\% of the sodium from FS with SS in bacon and summer sausage also resulted in an increase in salty taste when compared to a $100 \%$ FS control (Shazer et al., 2017). Umami and fruity-fermented attributes scored higher for the Treatment than Control (Table 3). The fruity-fermented attribute was not detected in the Control sample but was in the Treatment samples. Furthermore, of all of the sensory characteristics considered, the attribute fruity-fermented had the highest PCA correlation coefficient with saltiness (0.694). Smoke and meaty scores were higher for the Control. There were no differences for hardness and crosswise hardness between the Treatment and Control.

Table 3. Means for Study 1 trained sensory panel analysis $^{1}$ for emulsified frankfurters containing traditionally brewed SS containing $50 \% \mathrm{NaCl}$ from $\mathrm{FS}$ and $50 \% \mathrm{NaCl}$ from SS (Treatment) and a control frankfurter containing $100 \% \mathrm{NaCl}$ from $\mathrm{FS}$ and no SS (Control)

\begin{tabular}{llll}
\hline \hline & $\mathrm{C}^{2}$ & $\mathrm{TRT}^{2}$ & $\mathrm{SEM}^{3}$ \\
\hline Salt $^{4}$ & 5.19 & 5.97 & $0.05^{11}$ \\
Umami $^{5}$ & 2.14 & 2.30 & $0.02^{11}$ \\
Smoke $^{6}$ & 6.97 & 5.59 & $0.04^{11}$ \\
Meaty $^{7}$ & 8.13 & 7.30 & $0.04^{11}$ \\
Fruity Fermented $^{8}$ & 0.00 & 4.6 & $0.03^{11}$ \\
Hardness $^{9}$ & 8.48 & 8.49 & 0.03 \\
Crosswise Hardness $^{10}$ & 7.53 & 7.60 & 0.03 \\
\hline
\end{tabular}

${ }^{1}$ Ranked on a 15 -point scale with 0 indicating very little/weak and 15 indicating very much/strong for salty, umami, smoke, meaty, and fruityfermented; indicating very soft or very hard for hardness and crosswise hardness.

${ }^{2} \mathrm{C}=100 \%$ salt from FS; TRT $=50 \%$ salt from FS, $50 \%$ salt from SS.

${ }^{3} \mathrm{SEM}=$ standard error of the means for salty, umami, smoke, meaty, fruity-fermented, hardness, and crosswise hardness for emulsified frankfurters.

${ }^{4} \mathrm{Basic}$ taste simulated by sodium salts and other salts. $0.7 \% \mathrm{NaCl}$ solution $=4.5$.

${ }^{5}$ Basic taste simulated by glutamic acids; savory like. Glutamate solution $=1.5$.

${ }^{6}$ Aromatics associated with any hardwood such as hickory or apple; may be natural or artificial. Oscar Mayer beef frankfurter $=6.5$.

${ }^{7}$ Aromatics associated with the lean portion of cooked or roasted meat, including beef, pork, and/or poultry. Oscar Mayer (Madison, WI) beef frankfurter $=10.5$. Oscar Mayer beef/pork blend $=7.5$.

${ }^{8}$ Aromatics associated with fermented fruits with an undercurrent of sulfur. TRT $\sim 4.5$; canned pineapple.

${ }^{9}$ Force required to bring the front teeth completely together on first bite. Oscar Mayer beef frankfurter $=8$.

${ }^{10}$ Force required to bring the molar teeth completely together on first bite. Oscar Mayer beef frankfurter $=6$.

${ }^{11}$ Indicates mean values in row are significantly different at $\alpha<0.05$.

C, Control; FS, flake salt; SS, soy sauce; TRT, Treatment. 


\section{Aqueous and volatile fraction extraction and analysis: Study 1}

Although numerous compounds were resolved, based on the conditions and criteria set forth earlier, 7 compounds were identified using liquid chromatography-MS-2 dipeptides, 3 harmala alkaloids, 1 L- $\alpha$ amino acid, and 1 pyrrolidine (Table 4).

Two peptides were found to be unique to the Treatment samples, namely aspartyl-lysine and $\mathrm{N}-\gamma$ L-glutamyl-L-phenylalanine. Various peptides thought to contribute to flavor have previously been isolated from beef (Yamasaki and Maekawa, 1978; Tada et al., 1984). Aspartyl-lysine is a dipeptide resulting from incomplete protein catabolism that was shown to have a sour taste at $1.56 \mathrm{mM}$ and would likely be found in meat products (Tamura et al., 1989). Aspartyl-lysine was present in both the Treatment and Control samples but was present at higher levels in the Treatment. Glutamyl peptides from soy, notably $\gamma$-glutamylphenylalanine, can produce umami, bitter, and brothy flavors (Arai et al., 1972). Although $\gamma$-glutamylphenylalanine is a peptide commonly detected in soybeans, it was found in both Treatment and Control samples.

Multiple compounds from Maillard browning, including maltoxazine, pentosidine, and flazine, were detected in the aqueous fraction of both the Treatment and Control (Table 4) (Huyghues-Despointes et al., 1994; Hayase, 2007; Chao et al., 2009; Peiretti et al., 2011; Satoh et al., 2011). Maillard browning is a chemical reaction that occurs between a reducing sugar and an amino acid, wherein time and temperature catalyze the reaction affecting both the color and flavor of foods (Friedman, 1996). The cooking or roasting of meat and the heating of SS provided an environment for the Maillard reaction to occur (Hayase, 2007), resulting in the creation of various compounds detected. Pentosidine, an L- $\alpha$-amino acid, is a compound formed during the Maillard reaction (Peiretti et al., 2011) that has been detected in SS and cooked meat samples and contributes to the overall color of SS (Hayase, 2007; Chao et al., 2009). Maltoxazine was detected in both the Treatment and Control and is a product of the Amadori reaction that takes place during Maillard browning (Huyghues-Despointes et al., 1994). The harmala alkaloid flazine (Satoh et al., 2011) was also detected and is thought to contribute to the color of SS (Satoh et al., 2011).

An additional harmala alkaloid, 1-methyl-1,2,3,4tetrahydro- $\beta$-carboline-3-carboxylic acid (MTCA) was detected in this study and has been detected in many different food products and beverages (Herraiz,
Table 4. Comparison of aqueous profiles for Study 1 emulsified frankfurters containing traditionally brewed SS containing $50 \% \mathrm{NaCl}$ from $\mathrm{FS}$ and $50 \% \mathrm{NaCl}$ from SS (Treatment) and a control frankfurter containing $100 \% \mathrm{NaCl}$ from FS and no SS (Control)

\begin{tabular}{|c|c|c|c|c|c|}
\hline Compound $^{1}$ & $\begin{array}{c}\mathrm{RT} \\
(\mathrm{min})^{2}\end{array}$ & $\mathrm{~m} / \mathrm{z}^{3}$ & Ion $^{4}$ & $\begin{array}{c}\text { Fold } \\
\text { Change }^{5}\end{array}$ & $\begin{array}{l}\text { Molecular } \\
\text { Formula }\end{array}$ \\
\hline \multicolumn{6}{|l|}{ Dipeptides } \\
\hline Aspartyl-lysine ${ }^{6}$ & 5.511 & 262.1399 & $\mathrm{H}$ & 76 & $\mathrm{C}_{10} \mathrm{H}_{19} \mathrm{~N}_{3} \mathrm{O}_{5}$ \\
\hline $\begin{array}{l}\text { N- } \gamma \text {-L-glutamyl-L- } \\
\text { phenylalanine }\end{array}$ & 7.456 & 293.1137 & $\mathrm{H}$ & 65 & $\mathrm{C}_{14} \mathrm{H}_{18} \mathrm{~N}_{2} \mathrm{O}_{5}$ \\
\hline \multicolumn{6}{|l|}{ Harmala Alkaloids } \\
\hline $\begin{array}{l}\text { 1-methyl-1,2,3,4- } \\
\text { tetrahydro- } \beta \text {-carboline- } \\
3 \text {-carboxylic acid }{ }^{8}\end{array}$ & 9.454 & 229.0983 & $\mathrm{H}$ & 734 & $\mathrm{C}_{13} \mathrm{H}_{14} \mathrm{~N}_{2} \mathrm{O}_{2}$ \\
\hline $\begin{array}{l}\text { 1-methyl-1,2,3,4- } \\
\text { tetrahydro- } \beta \text {-carboline- } \\
3 \text {-carboxylic acid } * 8\end{array}$ & 9.467 & 265.0748 & $\mathrm{Cl}$ & 286 & $\mathrm{C}_{13} \mathrm{H}_{14} \mathrm{~N}_{2} \mathrm{O}_{2}$ \\
\hline Flazine $^{9}$ & 18.881 & 309.0874 & $\mathrm{H}$ & 105 & $\mathrm{C}_{17} \mathrm{H}_{12} \mathrm{~N}_{2} \mathrm{O}_{4}$ \\
\hline \multicolumn{6}{|l|}{$\alpha$-Amino Acid } \\
\hline Pentosidine $e^{10,11,12}$ & 7.874 & 377.1922 & $\mathrm{H}$ & 432 & $\mathrm{C}_{17} \mathrm{H}_{26} \mathrm{~N}_{6} \mathrm{O}_{4}$ \\
\hline \multicolumn{6}{|l|}{ Pyrrolidine } \\
\hline Maltoxazine $^{13}$ & 5.726 & 180.1022 & $\mathrm{H}$ & 60 & $\mathrm{C}_{10} \mathrm{H}_{13} \mathrm{NO}_{2}$ \\
\hline
\end{tabular}

${ }^{1}$ Compound $=$ compounds denoted with "*” were detected in TRT and not in $\mathrm{C}$, cited in footnotes 6-13.

${ }^{2}$ Average $(n=3)$ retention time (RT) of compounds detected in $\mathrm{C}$ and TRT.

${ }^{3}$ Mass to charge ratio as detected by LC-MS analysis.

${ }^{4}$ Ion combined with compound determined by Metlin database.

${ }^{5}$ Difference in abundance when comparing TRT to C.

${ }^{6}$ Tamura et al. (1989).

${ }^{7}$ Arai et al. (1972).

${ }^{8}$ Herraiz (1996).

${ }^{9}$ Satoh et al. (2011).

${ }^{10}$ Chao et al. (2009).

${ }^{11}$ Hayase (2007).

${ }^{12}$ Peiretti et al. (2011).

${ }^{13}$ Huyghues-Despointes et al. (1994).

C, Control; FS, flake salt; LC-MS, liquid chromatography-mass spectrometry; SS, soy sauce; TRT, Treatment.

1996). Herraiz (1996) evaluated cured ham and SS for the presence of MTCA and observed that SS had higher levels of MTCA compared to the cured ham. Similar results were observed in this study, wherein the Treatment had higher levels of MTCA. Herraiz (1996) detected MTCA in cured ham samples in a range of $0.02-0.21 \mu \mathrm{g} / \mathrm{g}$ compared to $20-87.6 \mathrm{mg} / \mathrm{L}$ in SS.

Table 5 presents and compares the volatile compounds detected in the Treatment and Control samples, as well as their odor quality. Fifty-six volatiles were positively detected: 27 terpenoids, 7 aldehydes, 6 esters, 4 hydrocarbon derivatives, 3 alcohols, 4 
ketones, 2 lactones, 2 furans, and 1 phenol. There were 30 volatiles detected at different levels in the Treatment and Control. Of the 56 total compounds, 28 have been previously detected in frankfurters (Chevance and Farmer, 1999; Feng et al., 2016).

Terpenoids, specifically monoterpenes, were the most commonly detected volatile compounds in the Treatment and Control. The large presence of terpenoids was determined to be due to the inclusion of spices during formulation, which included white pepper, nutmeg, ginger, coriander, and cardamom. Several researchers have confirmed the presence of these compounds in these and other spices. Steinhaus and Schieberle (2005) detected limonene, $\beta$-pinene, $\alpha$-pinene, linalool, 3-methylbutanal, and 2-methylbutanal in white pepper. An analysis by Schenk and Lamparsky (1981) showed that nutmeg oil contains dozens of terpene compounds and similar results exist for ginger (MacLeod and Pieris, 1984), coriander seed (Shahwar et al., 2012), and cardamom (Brennand and Heinz, 1970). Many of the terpenoids described above were detected in multiple spices.

The beef and pork also contributed to the volatile profile of the Treatment and Control samples, with results from several studies outlining specific compounds traditionally found in meat, typically from lipid oxidation pathways and thermal treatments. Hexanal, heptanal, and nonanal were all detected in cooked beef and cooked pork analyzed by Watanabe et al. (2015) and Rivas-Cañedo et al. (2011), respectively. Furfural and phenylacetaldehyde were additional volatiles detected in cooked beef samples (Watanabe et al., 2015). Furthermore, Rivas-Cañedo et al. (2011) detected the following compounds in cooked pork: 2-methylbutanal, 3-methylbutanal, 1-butanol, 2-methylbutan-1-ol, 3-methylbutan-1-ol, guaiacol, and butyrolactone. The peak area of hexanal was smaller in the Treatment than Control, and heptanal and furfural were not detected in the Treatment.

There was no difference in relative peak area between the Treatment and Control for nonanal, guaiacol, and phenylacetaldehyde. However, 2-methylbutanal, 3-methylbutanal, and butyrolactone had larger peak areas in the Treatment compared to Control, most likely resulting directly from the SS (Steinhaus and Schieberle, 2007; Feng et al., 2015). Although 1-butanol, 2-methyl-1-butanol, and 3-methyl-1-butanol were detected in cooked pork samples, they were not detected in the Control (Rivas-Cañedo et al., 2011). 1-butanol, 2-methyl-1-butanol, and 3-methyl1-butanol were detected in the Treatment and are key aroma compounds in SS (Feng et al., 2015). We expected to see alcohols in the Treatment because alcohols are one of the most abundant chemical classes of compounds in SS (Feng et al., 2015).

SS was the source of many of the volatile differences detected between the Treatment and Control as volatile compounds including 1-butanol, ethyl propionate, 3-methyl-1-butanol, 2-methyl-1butanol, ethyl 2-methylbutanoate, ethyl valerate, and ethyl 3-methylbutanoate were detected in Treatment and not in Control (Table 5). Furthermore, 3-methylbutanal, 2-methylbutanal, ethyl butanoate, and EHEX had larger peak areas in the Treatment compared to the Control. Although guaiacol and phenylacetaldehyde are volatile components found in SS, they are also found in pork and beef, respectively, which may have prevented significant differences in peak area from

Table 5. Comparison of volatile profiles for Study 1 emulsified frankfurters containing traditionally brewed SS containing $50 \% \mathrm{NaCl}$ from $\mathrm{FS}$ and $50 \% \mathrm{NaCl}$ from SS (Treatment) and a control frankfurter containing $100 \% \mathrm{NaCl}$ from FS and no SS (Control)

\begin{tabular}{|c|c|c|c|c|c|}
\hline \multirow[b]{2}{*}{ Compound $^{1}$} & \multirow[b]{2}{*}{ Average RT $(\min )^{2}$} & \multicolumn{2}{|c|}{ Average Peak Area } & \multirow[b]{2}{*}{$\mathrm{ID}^{2}$} & \multirow[b]{2}{*}{ Odor Quality $^{3}$} \\
\hline & & $\mathrm{C}$ & TRT & & \\
\hline \multicolumn{6}{|l|}{ Terpenoids } \\
\hline \multicolumn{6}{|l|}{ Monoterpenes } \\
\hline$\alpha$-thujene $e^{4,5,6}$ & 11.814 & $6,470,445$ & $7,835,904$ & 1 & Woody, green herb ${ }^{7}$ \\
\hline $1 \mathrm{R}-\alpha$-pinene ${ }^{5,6,8,9,10,11}$ & 11.988 & $31,257,357$ & $34,394,230$ & 1,2 & Spices, green, pine needles ${ }^{4}$ \\
\hline Camphene $4,5,6,9,12,13$ & 12.362 & $26,133,901$ & $28,238,319$ & 1,2 & Camphor, moth boll, oil, warm ${ }^{14}$ \\
\hline$\beta$-thujene ${ }^{12}$ & 12.966 & $7,796,800$ & $14,880,651$ & 1 & Spice $^{15}$ \\
\hline$\beta$-pinene ${ }^{4,5,6,9,10,11}$ & 13.05 & $29,811,104^{16}$ & $36,451,852^{1}$ & 1,2 & Pine, polish, wood ${ }^{14}$ \\
\hline$\beta$-phellandrene 4,10 & 13.343 & $9,533,260^{16}$ & $13,529,809^{1}$ & 1 & Mint, terpene-like ${ }^{7}$ \\
\hline$\alpha$-phellandrene ${ }^{4,5,9,10,12}$ & 13.676 & No data ${ }^{16}$ & $4,003,346^{1}$ & 1,2 & Citrus, fresh, mint, pepper, spice, wood ${ }^{14}$ \\
\hline 3 -carene $e^{4,5}$ & 13.819 & $37,540,903^{16}$ & $44,498,395^{1}$ & 1,2 & Lemon $^{14}$ \\
\hline
\end{tabular}


Table 5. (Continued)

\begin{tabular}{|c|c|c|c|c|c|}
\hline \multirow[b]{2}{*}{ Compound $^{1}$} & \multirow[b]{2}{*}{ Average RT $(\min )^{2}$} & \multicolumn{2}{|c|}{ Average Peak Area } & \multirow[b]{2}{*}{$\mathrm{ID}^{2}$} & \multirow[b]{2}{*}{ Odor Quality $^{3}$} \\
\hline & & $\mathrm{C}$ & TRT & & \\
\hline$\alpha$-terpinene $e^{4,5,9,10,12}$ & 13.957 & $1,550,730^{16}$ & $4,505,463^{1}$ & 1,2 & Lemon $^{14}$ \\
\hline p-cymene ${ }^{12,5,6,8}$ & 14.134 & $16,805,772^{16}$ & $21,516,813^{1}$ & 1,2 & Citrus, fresh, solvent ${ }^{14}$ \\
\hline Limonene $e^{5,6,8,9,11,12,13}$ & 14.236 & $43,230,920^{16}$ & $61,354,545^{1}$ & 1,2 & Citrus, mint $^{12}$ \\
\hline Eucalyptol & 14.304 & $93,795,446$ & $103,612,072$ & 1,2 & Camphor, cool, eucalyptol, $\operatorname{mint}^{14}$ \\
\hline$\gamma$-terpinene $e^{4,5,6,9}$ & 14.882 & $17,940,397^{16}$ & $22,724,510^{1}$ & 1,2 & Bitter, citrus ${ }^{14}$ \\
\hline cis- $\beta$-terpineol & 15.077 & $17,041,477$ & $18,549,655$ & 1 & Must $^{14}$ \\
\hline$\alpha$-terpinolene $e^{4,5,9}$ & 15.52 & $4,406,001^{16}$ & $6,053,794^{1}$ & 1,2 & Pine $^{14}$ \\
\hline Linalool $^{5,6,8,11,13}$ & 15.703 & $102,703,902$ & $118,346,925$ & 1,2 & Flowers, carnation ${ }^{4}$ \\
\hline d-camphor 6,13 & 16.738 & $7,993,839$ & $8,686,879$ & 1,2 & Camphor, earth, pine, spice ${ }^{14}$ \\
\hline Borneol $^{5,6,13}$ & 17.148 & $3,253,549$ & $3,532,131$ & 1,2 & Camphor, fragrant, green, must, polish ${ }^{14}$ \\
\hline Terpinen-4-ol ${ }^{5,8,10}$ & 17.342 & $35,606,004^{16}$ & $41,921,455^{1}$ & 1,2 & Earth, must, nutmeg, wood ${ }^{14}$ \\
\hline$\alpha$-terpineol $1^{5,6,8,10}$ & 17.585 & $8,431,000^{16}$ & $9,959,908^{1}$ & 1 & Anise, fresh, mint, oil ${ }^{14}$ \\
\hline Linalyl anthranilate & 18.663 & $3,009,888$ & $4,382,249$ & 1 & Floral $^{14}$ \\
\hline L- $\alpha$-bornyl acetate ${ }^{5,10}$ & 19.339 & $1,027,478$ & $1,017,456$ & 1 & Herb, pine, floral ${ }^{14}$ \\
\hline$\alpha$-terpinyl acetate ${ }^{5,8}$ & 20.404 & $39,835,989$ & $46,690,059$ & 1,2 & Herb, wax ${ }^{14}$ \\
\hline \multicolumn{6}{|l|}{ Sesquiterpenes } \\
\hline$\alpha$-copaene $e^{4,5}$ & 20.955 & $1,229,586$ & $1,323,600$ & 1 & Sweet, floral ${ }^{17}$ \\
\hline$\beta$-caryophyllene ${ }^{4,10}$ & 21.734 & $3,096,666^{16}$ & $4,522,721^{1}$ & 1,2 & Fried, spice, wood ${ }^{14}$ \\
\hline Ar-curcumene $e^{4,10}$ & 22.589 & $1,497,940^{16}$ & $1,855,327^{1}$ & 1 & Musty orange peel ${ }^{13}$ \\
\hline$\delta$-cadinene $e^{4,5,10}$ & 22.989 & $1,258,643$ & $1,230,156$ & 1 & Wood $^{15}$ \\
\hline \multicolumn{6}{|l|}{ Aldehydes } \\
\hline 3-methylbutanal ${ }^{9,10,12,13,18,19,20}$ & 3.342 & $3,928,352^{16}$ & $10,095,954^{1}$ & 1,2 & Malty \\
\hline 2-methylbutanal ${ }^{9,12,13,18,19,20}$ & 3.577 & $1,056,693^{16}$ & $4,007,478^{1}$ & 1,2 & Malty \\
\hline Hexanal $^{4,9,12,17,19}$ & 8.222 & $6,373,075^{1}$ & $3,175,453^{16}$ & 1,2 & Green $^{4}$ \\
\hline Furfural $1^{4,12,17,18}$ & 9.282 & $1,188,468^{1}$ & $\mathrm{nd}^{16}$ & 1,2 & Bread, sweet ${ }^{18}$ \\
\hline Heptanal $^{4,10,12,17}$ & 11.154 & $3,025,167$ & - & 1,2 & Citrus, fat, green, nut ${ }^{14}$ \\
\hline Phenylacetaldehyde ${ }^{17,18,20,21}$ & 14.576 & $2,092,865$ & $1,857,342$ & 1,2 & Berry, geranium, honey, nut, pungent ${ }^{14}$ \\
\hline Nonanal $1^{4,17,19}$ & 15.781 & $8,899,159$ & $7,649,162$ & 1,2 & Fat, floral, green, lemon ${ }^{14}$ \\
\hline \multicolumn{6}{|l|}{ Esters } \\
\hline Ethyl propionate ${ }^{9,13,18}$ & 5.194 & No data ${ }^{16}$ & $2,636,321^{1}$ & 1,2 & Fruity $^{18}$ \\
\hline Ethyl butanoate ${ }^{12}$ & 8.322 & $1,794,932^{16}$ & $10,305,58^{1}$ & 1,2 & $\begin{array}{l}\text { Apple, butter, cheese, pineapple, } \\
\text { strawberry }^{14}\end{array}$ \\
\hline Ethyl 2-methylbutanoate ${ }^{12,13}$ & 9.785 & No data ${ }^{16}$ & $1,424,382^{1}$ & 1,2 & Fruity \\
\hline Ethyl 3-methylbutanoate ${ }^{12,13}$ & 9.883 & No data ${ }^{16}$ & $1,887,668^{1}$ & 1,2 & Fruity \\
\hline Ethyl valerate ${ }^{12}$ & 11.157 & - & $6,166,341$ & 1,2 & Apple, dry fish, herb, nut, yeast ${ }^{14}$ \\
\hline Ethyl hexanoate $\mathrm{e}^{9,12}$ & 13.523 & $2,593,746^{16}$ & $15,054,983^{1}$ & 1,2 & $\begin{array}{l}\text { Apple peel, brandy, fruit gum, over-ripe } \\
\text { fruit, pineapple }{ }^{14}\end{array}$ \\
\hline \multicolumn{6}{|l|}{ Hydrocarbon Derivatives } \\
\hline Linalool oxide & 15.177 & $2,021,822$ & $1,717,853$ & 1,2 & Flowers $^{14}$ \\
\hline Safrole $^{5}$ & 19.407 & $2,319,256$ & $2,881,721$ & 1,2 & No data \\
\hline Myristicin $^{4,5}$ & 23.244 & $2,067,021$ & $2,266,121$ & 1,2 & Nutmeg-like ${ }^{17}$ \\
\hline Elemicin $^{4,5,12}$ & 23.648 & 787,209 & $1,605,334$ & 1,2 & Fruity $^{22}$ \\
\hline \multicolumn{6}{|l|}{ Alcohols } \\
\hline 1-butanol ${ }^{9,12,19}$ & 3.618 & No data ${ }^{16}$ & $11,506,118^{1}$ & 1,2 & Fruity $^{14}$ \\
\hline 3-methyl-1-butanol ${ }^{9,11,12,18,19,20}$ & 6.060 & No data ${ }^{16}$ & $16,558,660^{1}$ & 1,2 & Malty $^{6}$ \\
\hline 2-methyl-1-butanol ${ }^{11,12,18,19}$ & 6.201 & No data ${ }^{16}$ & $5,694,188^{1}$ & 1,2 & Fish oil, green, malt, onion, wine ${ }^{14}$ \\
\hline \multicolumn{6}{|l|}{ Ketones } \\
\hline 2-methyl-2-cyclopenten-1-one ${ }^{23}$ & 11.307 & $5,568,730$ & $4,390,053$ & 1,2 & No data \\
\hline 3-methyl-2-cyclopenten-1-one ${ }^{24}$ & 12.798 & $6,692,460$ & $4,963,392$ & 1,2 & Fruit $^{14}$ \\
\hline 6-methyl-5-heptene-2-one ${ }^{4}$ & 13.258 & $4,535,903$ & $4,983,828$ & 1,2 & $\begin{array}{l}\text { Citrus, mushroom, pepper, rubber, } \\
\text { strawberry }^{14}\end{array}$ \\
\hline 2,3-dimethyl-2-cyclopenten-1-one $e^{4,23}$ & 14.471 & $6,016,604^{1}$ & $5,402,217^{16}$ & 1,2 & Herbaceous $^{21}$ \\
\hline
\end{tabular}


Table 5. (Continued)

\begin{tabular}{|c|c|c|c|c|c|}
\hline \multirow[b]{2}{*}{ Compound $^{1}$} & \multirow[b]{2}{*}{ Average RT $(\mathrm{min})^{2}$} & \multicolumn{2}{|c|}{ Average Peak Area } & \multirow[b]{2}{*}{$\mathrm{ID}^{2}$} & \multirow[b]{2}{*}{ Odor Quality $^{3}$} \\
\hline & & $\mathrm{C}$ & TRT & & \\
\hline \multicolumn{6}{|l|}{ Lactones } \\
\hline Butyrolactone $\mathrm{e}^{12,19,23}$ & 11.531 & $5,751,377^{1}$ & $2,887,807^{16}$ & 1,2 & Caramel, cheese, roasted nut ${ }^{14}$ \\
\hline 2,5-dihydro-3,5-dimethyl-2-furanone ${ }^{23}$ & 13.618 & $6,906,369^{1}$ & $5,197,240^{16}$ & 1 & No data \\
\hline \multicolumn{6}{|l|}{ Furans } \\
\hline Acetylfuran ${ }^{23,24}$ & 11.433 & $4,406,754$ & $3,313,160$ & 1,2 & Raw potatoes, stale, metallic ${ }^{4}$ \\
\hline 2-methyl-5-ethylfuran & 14.075 & $1,097,979^{1}$ & $862,917^{16}$ & 1 & No data \\
\hline \multicolumn{6}{|l|}{ Phenol } \\
\hline Guaiacol $^{4,13,18,19,20,23}$ & 15.557 & $6,607,618$ & $5,960,949$ & 1,2 & Smoke, frankfurter, plastic; burnt ${ }^{4,6}$ \\
\hline
\end{tabular}

${ }^{1}$ Compounds previously identified in various food or ingredient systems cited in footnotes 6-25.

${ }^{2}$ ID: 1 = Match with National Institute of Standards and Technology database; 2 = Match with retention time (RT) of known standard.

${ }^{3}$ Odor quality identified in various foods from previous research cited in footnotes 6-25.

${ }^{4}$ Chevance and Farmer (1999).

${ }^{5}$ Schenk and Lamparsky (1981).

${ }^{6}$ Shahwar et al. (2012).

${ }^{7} \mathrm{Li}$ et al. (2011).

${ }^{8}$ Brennand and Heinz (1970).

${ }^{9}$ Feng et al. (2016).

${ }^{10}$ MacLeod and Pieris (1984).

${ }^{11}$ Steinhaus and Schieberle (2005).

${ }^{12}$ Average peak area of compound in C or TRT $(n=3)$ are different $(P<0.05)$.

${ }^{13}$ Kaneko et al. (2013).

${ }^{14}$ Flavor Ingredient Library (2018)

${ }^{15}$ Xiao et al. (2016).

${ }^{16}$ Average retention time of compounds in C and TRT $(n=3)$.

${ }^{17}$ Watanabe et al. (2015).

${ }^{18}$ Feng et al. (2015).

${ }^{19}$ Rivas-Cañedo et al. (2011).

${ }^{20}$ Steinhaus and Schieberle (2007).

${ }^{21}$ Guyot et al. (1998)

${ }^{22}$ Wang et al. (2007).

${ }^{23}$ Montazeri et al. (2013).

${ }^{24}$ Guillen et al. (1995).

C, Control; FS, flake salt; SS, soy sauce; TRT, Treatment.

being observed (Rivas-Cañedo et al. 2011; Feng et al., 2015; Watanabe et al., 2015).

The liquid smoke solution used also contributed to the volatile profile. Guaiacol, 2-methyl-2-cyclopenten1-one, 3-methyl-2-cyclopenten-1-one, acetylfuran, and furfural are typical components found in liquid smoke (Guillen et al., 1995). An analysis of liquid smoke (Montazeri et al., 2013) identified the following compounds that were also found in the Treatment and Control: guaiacol, 2-methyl-2-cyclopenten-1-one, 2,3dimethyl-2-cyclopenten-1-one, acetylfuran, butyrolactone, and 2,5-dihydro-3,5-dimethyl-2-furanone. There was no difference in peak area between the Treatment and Control for guaiacol, 2-methyl-2-cyclopenten-1- one, 3-methyl-2-cyclopenten-1-one, and acetylfuran (Table 5). A few compounds, including furfural, 2,3dimethyl-2-cylopenten-1-one, 2-methyl-5-ethylfuran, and 2,5-dihydro-3,5-dimethyl-2-furanone, were present at higher levels in the Control compared to the Treatment.

The volatile profiles of Treatment and Control were representative of compounds previously detected in the raw materials, spices, SS, and liquid smoke and were characterized as a means to explain the sensory results and saltiness potentiation phenomenon. The sensory results revealed that the Treatment had higher saltiness scores than Control, with saltiness possibly being correlated with the fruity-fermented aroma 
detected in the Treatment through PCA. Compounds found in the study with known fruity aromas included 1-butanol, ethyl propionate, ethyl 2-methylbutanoate, and ethyl 3-methylbutanoate, detected in the Treatment and not in Control. EHEX and ethyl butanoate also have fruity aromas and were present at higher levels in the Treatment.

\section{Correlation of sensory and instrumental data: Study 1}

PCA was conducted to determine correlations between the sensory characteristic saltiness and the volatile compounds detected in the Treatment and Control (Table 6). From a total of 56 volatile compounds detected in the Treatment and Control samples, only 30 were detected at different levels in the Treatment and Control samples, therefore all $30 \mathrm{com}-$ pounds were included in the PCA analysis. From this PCA, EHEX had the highest correlation to the sensory attribute saltiness with a correlation value of 0.818 . Additionally, ethyl butanoate was suggested to possibly contribute to the saltiness potentiation based on a correlation value of 0.807 . EHEX and ethyl butanoate are esters described as having odor characteristics of apple peel, brandy, over-ripe fruit, and pineapple (EHEX) and apple, butter, cheese, pineapple, and strawberry (ethyl butanoate) (Flavor Ingredient Library, 2018). Furthermore, PCA for the sensory attributes exhibited a strong positive relationship between saltiness and fruity-fermented, which we propose resulted from the aroma of the esters noted above. The correlation of EHEX and ethyl butanoate with saltiness, the odor quality characteristics of these compounds, and the correlation between salty taste and fruity-fermented aroma provided strong evidence that these esters were responsible - at least in part-for the saltiness potentiation observed in the Treatment samples. The discovery that SS enhances perceived saltiness via its fruity odor quality is in agreement with Imamura's findings in which a fruity aroma was uniquely found in Japanese SS, most of which were made with a traditional brewing process (Imamura, 2016). Those SS samples were also differentiated themselves from other types of SS by their saltier taste. PCA was also conducted on the sensory characteristic salt and the aqueous compounds detected in the Treatment and Control. However, a stronger correlation was observed with EHEX, therefore additional studies aiming to confirm the ability of a specific compound to potentiate saltiness focused on this singular ester.
Table 6. PCA for Study 1 volatile compounds and saltiness as a sensory characteristic for emulsified frankfurters $(n=4)$ containing traditionally brewed SS containing $50 \% \mathrm{NaCl}$ from $\mathrm{FS}$ and $50 \% \mathrm{NaCl}$ from SS (TRT) and a control frankfurter containing $100 \% \mathrm{NaCl}$ from FS and no SS (C)

\begin{tabular}{|c|c|}
\hline Volatile Compound $^{1}$ & Correlation with Saltiness $^{2}$ \\
\hline Ethyl hexanoate & 0.818 \\
\hline Ethyl butanoate & 0.807 \\
\hline 3-methyl-1-butanol & 0.743 \\
\hline$\beta$-pinene & 0.741 \\
\hline$\alpha$-terpineol & 0.739 \\
\hline 2-methyl-1-butanol & 0.737 \\
\hline Ethyl valerate & 0.735 \\
\hline$\alpha$-phellandrene & 0.731 \\
\hline p-cymene & 0.725 \\
\hline Ethyl propionate & 0.706 \\
\hline 1-butanol & 0.706 \\
\hline$\gamma$-terpinene & 0.701 \\
\hline Ethyl 3-methylbutanoate & 0.701 \\
\hline Ethyl 2-methylbutanoate & 0.697 \\
\hline$\alpha$-terpinene & 0.697 \\
\hline 2-methylbutanal & 0.681 \\
\hline 3-methylbutanal & 0.678 \\
\hline Terpinen-4-ol & 0.662 \\
\hline$\alpha$-terpinolene & 0.660 \\
\hline Limonene & 0.659 \\
\hline 3-carene & 0.588 \\
\hline Ar-curcumene & 0.543 \\
\hline$\beta$-phellandrene & 0.502 \\
\hline$\beta$-caryophyllene & 0.360 \\
\hline 2-methyl-5-ethylfuran & -0.062 \\
\hline 2,3-dimethyl-2-cyclopenten-1-one & -0.283 \\
\hline 2-furanone 2,5-dihydro-3,5-dimethyl & -0.320 \\
\hline Butyrolactone & -0.345 \\
\hline Hexanal & -0.403 \\
\hline Heptanal & -0.681 \\
\hline Furfural & -0.867 \\
\hline
\end{tabular}

${ }^{1}$ Volatile compounds as identified in as being different $(\alpha<0.05)$ between the TRT and C.

${ }^{2}$ Correlation values of volatile compounds with saltiness as calculated by PCA.

C, Control; FS, flake salt; PCA, principal component analysis; SS, soy sauce; TRT, Treatment.

\section{Confirmatory studies: EHEX and saltiness potentiation: Study 2}

Odor threshold values of EHEX vary across food products ranging from $1.2 \mu \mathrm{g} / \mathrm{kg}$ in water to $40 \mu \mathrm{g} / \mathrm{kg}$ in oil (Van Gemert, 2011; Conde-Martínez et al., 2013). Based on these values, $10 \mu \mathrm{g} / \mathrm{kg}$ (Treatment 1), $20 \mu \mathrm{g} / \mathrm{kg}$ (Treatment 2), and $50 \mu \mathrm{g} / \mathrm{kg}$ (Treatment 3) of EHEX along with a Control (no EHEX) 
were selected for investigation, and trained panel studies with these Treatments and Control were conducted.

\section{Physicochemical and qualitative analyses: Study 2}

Proximate analysis (data not shown) revealed that the values for moisture (56\%), protein $(12 \%)$, and fat $(29 \%)$ were similar to those observed in the first study, as well as to values observed in commercial frankfurters (Sebranek et al., 2001). Although the $L^{*}, a^{*}$, and $b^{*}$ color measurement values (data not shown) were statistically different when comparing Treatment 1 to Control, the $\Delta \mathrm{E}^{*}{ }_{\mathrm{ab}}$ value was 1.13 , meaning that it would be difficult to visually detect differences (Luft, 2016). There were no significant differences (data not shown) between the Treatments and Control for $\mathrm{pH}$ or percent salt: $\mathrm{pH}$ values ranged from 6.03 (Treatment 3 ) to 6.08 (Control) and percent salt ranged from 2.70 (Treatment 1) to 2.73 (Treatment 2). Purge, emulsion stability, and cook yields were measured for the entire batch within each replication with average values of $0.90 \%, 4.36 \%$, and $88.70 \%$, respectively (data not shown). There were no significant differences between the Treatments and Control for textural measurements (data not shown) with the following ranges of values: hardness 49.41 (Treatment 2) to 52.08 (Control), springiness 75.40 (Treatment 2) to 76.60 (Treatment 3), cohesiveness 65.17 (Control) to 66.02 (Treatment 1), chewiness 23.60 (Treatment 2) to 26.12 (Treatment 1), and puncture 3.47 (Treatment 1) to 3.68 (Control). These results suggest that EHEX had an insignificant impact on frankfurter physicochemical properties at the concentrations evaluated in this study.

\section{Trained sensory panel: Study 2}

The addition of EHEX to frankfurters affected saltiness perception, in that Treatment 1 was saltier than the Control (Figure 1). However, a nonlinear relationship was observed for EHEX concentration, saltiness perception, and fermented/sour aromatic perception. The change in saltiness perception may be a result of aroma perception changing as EHEX concentration changed. A similar phenomenon was observed by Moncrieff (1967) when assessing various compounds for their odor at dilute and concentrated levels. Diphenyl methane, for example, exhibited an orange odor when concentrated and a geranium odor when dilute. Furthermore, under dilute conditions, furfuryl mercaptan has a roasted coffee odor but displays an offensive odor when concentrated (Moncrieff, 1967). The changing aroma of these compounds at different

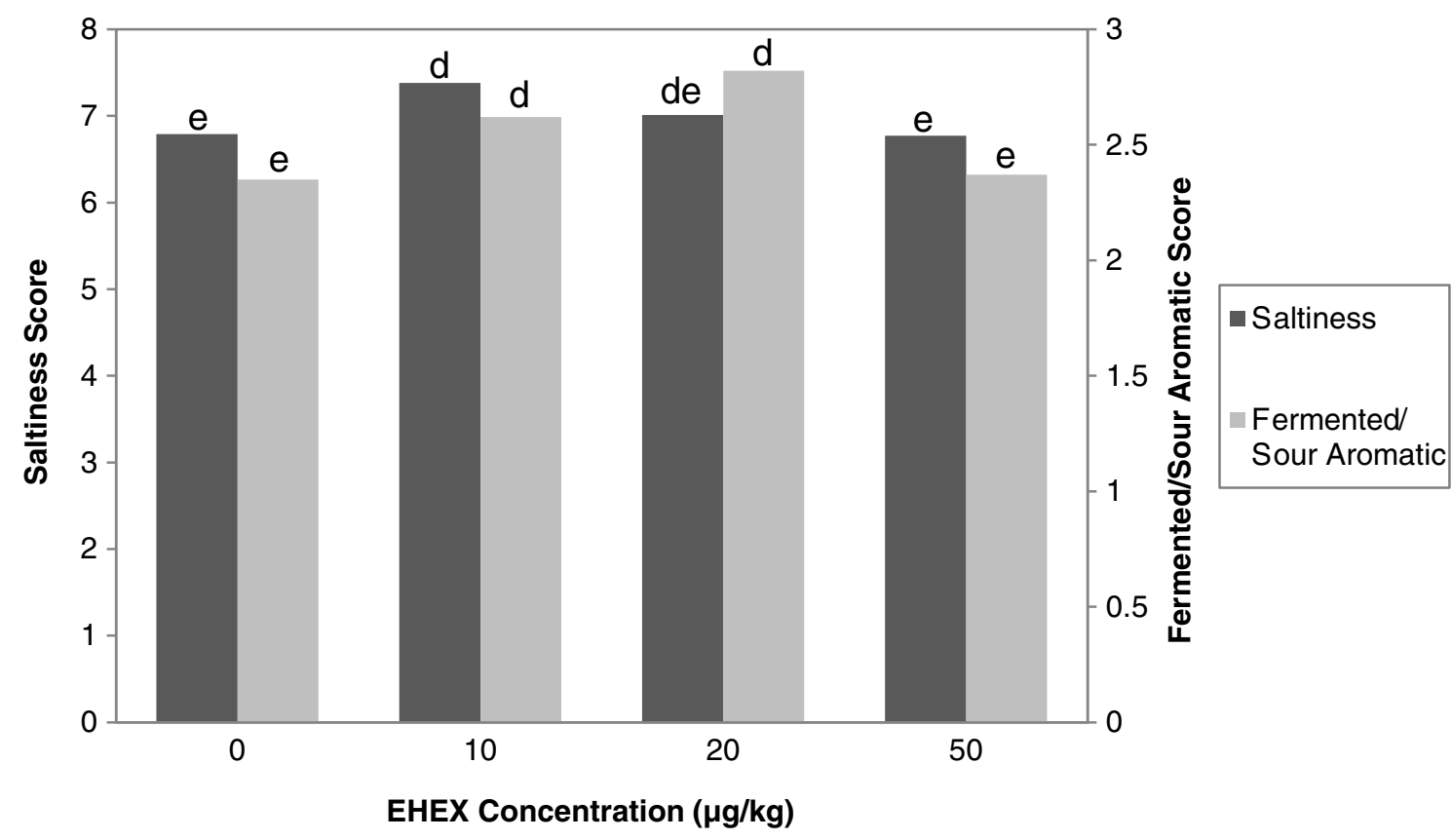

Figure 1. Saltiness and fermented/sour aromatic scores for trained sensory analysis for Study 2 in frankfurters containing ethyl hexonate (EHEX) Basic salty taste stimulated by sodium salts and other salts; $0.7 \% \mathrm{NaCl}$ solution $=4.5$. Aromatics associated with fermented or sour foods, that may or may not be fruity, with an undercurrent of sulfur; control sample $=\sim 2.1$; canned pineapple. Treatments $(2.5 \% \mathrm{NaCl})$ : Control $=0 \mu \mathrm{g} / \mathrm{kg}$ EHEX; Treatment $1=10$ $\mu \mathrm{g} / \mathrm{kg}$ EHEX; Treatment $2=20 \mu \mathrm{g} / \mathrm{kg}$ EHEX; and Treatment $3=50 \mu \mathrm{g} / \mathrm{kg}$ EHEX. ${ }^{\mathrm{d}, \mathrm{e}}$ Means for the same sensory attribute with different superscripts are different $(\alpha<0.05)$. 
concentrations demonstrates that odor response changes with concentration. A similar phenomenon may have occurred for EHEX, with the odor perception changing with concentration such that EHEX did not exhibit the same fruity-fermented aroma at lower and higher concentrations. The relationship between concentration and aroma perception is further demonstrated by Brossard et al. (2002a, 2002b), who studied oil in water emulsions containing various volatile compounds to understand the relationship between odor intensity and concentration. Fechner's law, which follows a logarithmic curve, and Hill's model, following a sigmoidal curve, were used to graphically represent their results for compound concentration and odor intensity (Fechner, 1860; Hill, 1913; Brossard et al., 2002a, 2002b).

Previous studies have demonstrated that compounds with fruity or sweet aromas, similar to the aroma of EHEX, have the ability to enhance perceived taste modalities in food systems (Frank and Byram, 1988; Stevenson et al., 1999; Djordjevic et al., 2004). The ability of certain compounds to enhance sweetness perception is likely due to odor-induced, cross-modal interactions (Djordjevic et. al., 2004). Cross-modal interactions occur when multiple senses are simultaneously stimulated and interact with one another to affect the perceived taste perception (Delahunty and Drake, 2004). Cross-modal relationships are typically generated from previous experiences and learned associations (Dalton et al., 2000; Prescott et al., 2004). Learned associations occur when an aroma stimulus is repeatedly and simultaneously experienced with a specific taste stimulus (Stevenson et al., 1998; Stevenson et al., 2000).

The fruity-fermented aroma identified in Study 1 and exhibited by EHEX addition in Study 2 showed strong evidence that it affects saltiness potentiation as a result of learned associations and cross-modal interactions. Potentially, such interactions in frankfurters are enabled through the common use of condiments such as ketchup, mustard, and pickle relish. Tomato ketchup is found in $97 \%$ of households and is made from strained tomatoes, salt, sugar, vinegar, spices, onions, and garlic (Haynes, 2003; Sharoba et al., 2005). Flavor terms used to describe ketchup and processed tomato products include tomato, fermented, fruity, browned, cardboard, green-viney, musty/earthy, ripeness, and cooked (Hongsoongnern and Chambers, 2008). American-style mustard and pickle brines are made with sugar and vinegar (Lang, 1995; Akbudak et al., 2007). Ketchup, mustard, and pickles contain vinegar, which could contribute more to the fermented/sour aroma observed. The addition of various condiments with fruity aroma-including SS to complement foods or the addition of fruity aromainducing compounds directly to food formulationsmay induce this learned association with saltiness perception under a particular range of fruity odor intensity. Analysis of variance showed that EHEX concentrations affected saltiness perception $(P=0.0013)$. Due to the complicated model and design of the experiment, the study was entirely replicated and data analyzed to account for all measurable sources of variation. This analysis, again, revealed that EHEX concentration affects saltiness perception $(P<0.0001)$. Treatment 1 was saltier $(P<0.05)$ and had higher $(P<0.05)$ fermented/sour aromatic scores than the Control (Figure 1), which is similar to the results observed in Study 1 in which the Treatment had a fruity-fermented aroma and was saltier than the Control. Ten micrograms per kilogram is within the odor threshold range for EHEX, which is $1.2 \mu \mathrm{g} / \mathrm{kg}$ to $40 \mu \mathrm{g} / \mathrm{kg}$ in water and oil, respectively; Conde-Martínez et al., 2013). These findings suggest that low levels of fruitiness aromainducing compounds may be able to induce saltiness perception through learned associations.

\section{Conclusions}

This research confirmed the ability of SS to potentiate saltiness in frankfurters with minimal impact on other important quality attributes. Furthermore, a possible mechanism was identified by which the saltiness potentiation phenomenon observed in frankfurters containing SS may be, at least in part, reasonably explained. These results suggest that lower levels of EHEX have the ability to contribute to saltiness potentiation in frankfurters through learned associations.

\section{Acknowledgments}

This project was funded by Kikkoman USA R\&D Laboratory, Inc.

\section{Literature Cited}

Akbudak, B., M. H. Ozer, V. Uylaser, and B. Karaman. 2007. The effect of low oxygen and high carbon dioxide on storage and pickle production of pickling cucumbers cv. 'Octobus.' J. Food Eng. 78:1034-1046. https://doi.org/10.1016/j. jfoodeng.2005.12.045.

AOAC International. 2000a. Official methods of analysis of the association of official analytical chemists. 17th ed. Method 
No. 950.46, Moisture in meat and meat products. AOAC, Gaithersburg, MD.

AOAC International. 2000b. Official methods of analysis of the association of official analytical chemists. 17th ed. Method No. 990.03, Protein (crude) in animal feed combustion method. AOAC, Gaithersburg, MD.

AOAC International. 2000c. Official methods of analysis of the association of official analytical chemists. 17th ed. Method No. 991.36, Fat (crude) ether extract in meat. AOAC, Gaithersburg, MD.

Arai, S., M. Yamashita, and M. Fujimaki. 1972. Glutamyl oligopeptides as factors responsible for tastes of a proteinasemodified soybean protein. Agric. Biol. Chem. 36:12531256. https://doi.org/10.1080/00021369.1972.10860400.

Bourne, M. C. 1978. Texture profile analysis. Food Technol. 32:66-72.

Brennand, C., and D. Heinz. 1970. Effects of pH and temperature on volatile constituents of cardamom. J. Food Sci. 35:533-537. https://doi.org/10.1111/j.1365-2621.1970. tb04801.x.

Brossard, C., F. Rousseau, G. Llamas, and J. Dumont. 2002a. Determination of sensory oil-water partition coefficients of single aroma compounds combining panelist free intensity rating and theoretical modeling of odor. J. Sens. Stud. 17:445-460. https://doi.org/10.1111/j.1745-459X.2002. tb00358.x.

Brossard, C., F. Rousseau, G. Llamas, and J. Dumont. 2002b. Odor perception over liquid emulsion containing single aroma compounds: effects of aroma concentration and oil volume fraction. J. Sens. Stud. 17:511-525. https://doi.org/10.1111/j. 1745-459X.2002.tb00362.x.

Chao, P., C. Hsu, and M. Yin. 2009. Analysis of glycative products in sauce and sauce-treated foods. Food Chem. 113:262-266. https://doi.org/10.1016/j.foodchem.2008.06.076.

Chevance, F. F., and L. J. Farmer. 1999. Identification of major volatile odor compounds in frankfurters. J. Agr. Food Chem. 47:5151-5160. https://doi.org/10.1021/jf990515d.

Conde-Martínez, N., A. Jiménez, M. Steinhaus, P. Schieberle, D. Sinuco, and C. Osorio. 2013. Key aroma volatile compounds of gulupa (Passiflora edulis Sims fo edulis) fruit. Eur. Food Res. Technol. 236:1085-1091. https://doi.org/10.1007/ s00217-013-1979-9.

Dalton, P., N. Doolittle, H. Nagata, and P. A. S. Breslin. 2000. The merging of the senses: Integration of subthreshold taste and smell. Nat. Neurosci. 3:431-432.

Delahunty, C. M., and M. A. Drake. 2004. Sensory character of cheese and its evaluation. Cheese: Chemistry, Physics and Microbiology. 1:455-487. https://doi.org/10.1016/S1874558X(04)80078-2.

Desmond, E. 2006. Reducing salt: A challenge for the meat industry. Meat Sci. 74:188-96. https://doi.org/10.1016/j.meatsci. 2006.04.014.

Djordjevic, J., R. J. Zatorre, and M. Jones-Gotman. 2004. Odorinduced changes in taste perception. Exp. Brain Res. 159:405-408. https://doi.org/10.1007/s00221-004-2103-y.

Fechner, G. T. 1860. Elemente de psychophysik. In: Breitkopf and Härtel, editors, Evaluation sensorielle: Manuel methodoloque. 1990. Grandeur du Stimulus et Intensite de la
Sensation au Niveau Supra-Liminaire, Lavoisier, Paris and Leipzig, Germany. p. 16-21.

Feng, X., J. G. Sebranek, H. Y. Lee, and D. U. Ahn. 2016. Effects of adding red wine on the physicochemical properties and sensory characteristics of uncured frankfurter-type sausage. Meat Sci. 121:285-291. https://doi.org/10.1016/j.meatsci. 2016.06.027.

Feng, Y., G. Su, H. Zhao, Y. Cai, C. Cui, D. Sun-Waterhouse, D., and M. Zhao. 2015. Characterisation of aroma profiles of commercial soy sauce by odour activity value and omission test. Food Chem. 167:220-228. https://doi.org/10.1016/j. foodchem.2014.06.057.

Flavor Ingredient Library. 2018. Flavor and Extract Manufacturers Association. https://www.femaflavor.org/flavor-library. (Accessed 12 March 2020).

Frank, R. and J. Byram. 1988. Taste-smell interactions are tastant and odorant dependent. Chem. Senses. 13:445-455. https:// doi.org/10.1093/chemse/13.3.445.

Friedman, M. 1996. Food browning and its prevention: An overview. J. Agr. Food Chem. 44:631-653. https://doi.org/10. 1021/jf950394r.

Guillen, M. D., M. J. Manzanos, and L. Zabala. 1995. Study of a commercial liquid smoke flavoring by means of gas chromatography/mass spectrometry and Fourier transform infrared spectroscopy. J. Agr. Food Chem. 43:463-468. https://doi. org/10.1021/jf00050a039.

Guyot, C., A. Bouseta, V. Scheirman, and S. Collin. 1998. Floral origin markers of chestnut and lime tree honeys. J. Agr. Food Chem. 46:625-633. https://doi.org/10.1021/jf9705101.

Hayase, F. 2007. Recent development of 3-deoxyosone related Maillard reaction products. Food Sci. Technol. Res. 6:79-86.

Haynes, M. 2003. Ketchup. Restaurant Business. 102:67-71.

Herraiz, T. 1996. Occurrence of tetrahydro- $\beta$-carboline-3-carboxylic acids in commercial foodstuffs. J. Agr. Food Chem. 44:3057-3065. https://doi.org/10.1021/jf960043s.

Hill, A. V. 1913. The combinations of haemoglobin with oxygen and with carbon monoxide. I. Biochem. J. 7: 471-480.

Hongsoongnern, P., and E. Chambers 2008. A lexicon for texture and flavor characteristics of fresh and processed tomatoes. J. Sens. Stud. 23:583-599. https://doi.org/10.1111/j.1745459X.2008.00174.x.

Hutton, T. 2002. Sodium technological functions of salt in the manufacturing of food and drink products. Brit. Food J. 104:126-152. https://doi.org/10.1108/00070700210423635.

Huyghues-Despointes, A., V. A. Yaylayan, and A. Keyhani. 1994. Pyrolysis/GC/MS analysis of 1-[(2'-carboxyl) pyrrolidinyl]1-deoxy-D-fructose (proline Amadori compound). J. Agr. Food Chem. 42:2519-2524. https://doi.org/10.1021/ jf00047a027.

Imamura, M. 2016. Descriptive terminology for the sensory evaluation of soy sauce. J. Sens. Stud. 31:393-407. https://doi.org/ 10.1111/joss. 12223 .

Kaneko, S., K. Kumazawa, and O. Nishimura. 2013. Studies on the key aroma compounds in raw (unheated) and heated Japanese soy sauce. J. Agr. Food Chem. 61:3396-402. https://doi.org/ $10.1021 /$ jf400353h. 
Kremer, S., J. Mojet, and R. Shimojo. 2009. Salt reduction in foods using naturally brewed soy sauce. J. Food Sci. 74:S255-S262. https://doi.org/10.1111/j.1750-3841.2009.01232.x.

Kuhn, M. E. 2010. Strategies for reducing sodium in the U.S. Institute of Food Technologists. https://www.ift.org/newsand-publications/food-technology-magazine/issues/2010/ may/features/strategies-for-reducing-sodium-in-the-u-s. (Accessed 14 March 2020).

Lang, J. 1995. Mustard: This flavorful condiment is indispensable on hot dogs and tastes great with a lot of other foods, too. Restaurant Business. 94:90-94.

Leksrisompong, P., R. Miracle, and M. Drake. 2010. Characterization of flavor of whey protein hydrolysates. J. Agr. Food Chem. 58:6318-6327. https://doi.org/10.1021/ jf100009u.

Li, X., B. Yu, P. Curran, and S. Q. Liu. 2011. Chemical and volatile composition of mango wines fermented with different Saccharomyces cerevisiae yeast strains. South African Journal of Enology and Viticulture. 32:117-128. https://doi. org/10.21548/32-1-1371.

Luft, P. 2016. Delta E 101. http://zschuessler.github.io/DeltaE/ learn/. (Accessed 12 March 2020).

Luh, B. S. 1995. Industrial production of soy sauce. J. Ind. Microbiol. 14:467-471.

MacLeod, A. J., and N. M. Pieris, N. M. 1984. Volatile aroma constituents of Sri Lankan ginger. Phytochemistry. 23:353-359. https://doi.org/10.1016/S0031-9422(00)80332-5.

McGough, M. M., T. Sato, S. A. Rankin, and J. J. Sindelar. 2012a. Reducing sodium levels in frankfurters using naturally brewed soy sauce. Meat Sci. 91:69-78. https://doi.org/10.1016/j. meatsci.2011.12.008.

McGough, M. M., T. Sato, S. A. Rankin, and J. J. Sindelar. 2012b. Reducing sodium levels in frankfurters using a natural flavor enhancer. Meat Sci. 91:185-194. https://doi.org/10.1016/j. meatsci.2012.01.018.

Meilgaard, M.C., G. V. Civille, and B. T. Carr. 2007. The Spectrum $^{\mathrm{TM}}$ descriptive analysis method. In: M. C. Meilgaard, G. V. Civille, and B. T. Carr, editors, Sensory evaluation techniques. CRC Press, Boca Raton, FL. p 189253.

Moncrieff, R.W. 1944. The chemical senses. Leonard Hill, London.

Montazeri, N., A. Oliveira, B. Himelbloom, M. Leigh, and C. Crapo. 2013. Chemical characterization of commercial liquid smoke products. Food Science \& Nutrition. 1:102-115. https://doi.org/10.1002/fsn3.9.

Peiretti, P. G., C. Medana, S. Visentin, V. Giancotti, V. Zunino, and G. Meineri. 2011. Determination of carnosine, anserine, homocarnosine, pentosidine and thiobarbituric acid reactive substances contents in meat from different animal species. Food Chem. 126:1939-1947. https://doi.org/10.1016/j. foodchem.2010.12.036.

Prescott, J., V. Johnstone, and J. Francis. 2004. Odor-taste interactions: effects of attentional strategies during exposure. Chem. Senses. 29:331-340. https://doi.org/10.1093/chemse/bjh036.

Qu, S., G. Barrett-Wilt, L. M. Fonseca, and S. Rankin. 2016. A profile of sphingolipids and related compounds tentatively identified in yak milk. J. Dairy Sci. 99:5083-5092. https://doi.org/ 10.3168/jds.2015-10431.
Richards, M. P., A. M. Modra, and R. Li. 2002. Role of deoxyhemoglobin in lipid oxidation of washed cod muscle mediated by trout, poultry and beef hemoglobins. Meat Sci. 62:157-163. https://doi.org/10.1016/s0309-1740(01) 00242-x

Rivas-Cañedo, A., C. Juez-Ojeda, M. Nuñez, and E. FernándezGarcía. 2011. Effects of high-pressure processing on the volatile compounds of sliced cooked pork shoulder during refrigerated storage. Food Chem. 124:749-758. https://doi. org/10.1016/j.foodchem.2010.06.091.

Rust, R. E. 1987. Sausage products. In: J. F. Price, and B. S. Schweigert, editors, The science of meat and meat products. 3rd ed. Food and Nutrition Press, Inc., Westport, CT. p $457-$ 485.

Satoh, M., Y. Nomi, S. Yamada, M. Takenaka, H. Ono, and M. Murata. 2011. Identification of 2, 4-dihydroxy-2, 5-dimethyl-3 (2H)-thiophenone as a low-molecular-weight yellow pigment in soy sauce. Biosci. Biotech. Bioch. 75:1240-1244. https://doi.org/10.1271/bbb.100867.

Schenk, H. P., and D. Lamparsky. 1981. Analysis of nutmeg oil using chromatographic methods. J. Chromatogr. A. 204:391-395. https://doi.org/10.1016/S0021-9673(00)81684-2.

Sebranek, J. G., S. M. Lonergan, M. King-Brink, and E. Larson. 2001. Meat science and processing. 3rd ed. Peerage Press, Zenda, WI.

Shahwar, M., A. El-Ghorab, F. Anjum, M. Butt, S. Hussain, and M. Nadeem. 2012. Characterization of coriander (Coriandrum sativum L.) seeds and leaves: Volatile and non volatile extracts. Int. J. Food Prop. 15:736-747. https://doi.org/10. 1080/10942912.2010.500068.

Sharoba, A. M., B. Senge, H. A. El-Mansy, H. E. Bahlol, and R. Blochwitz. 2005. Chemical, sensory and rheological properties of some commercial German and Egyptian tomato ketchups. Eur. Food Res. Technol. 220:142-151. https://doi.org/ 10.1007/s00217-004-0981-7.

Shazer, W. H., L. A. Jiminez-Maroto, T. Sato, S. A. Rankin, and J. J. Sindelar. 2017. Reducing sodium in processed meats using traditionally brewed soy sauce and fermented flavor enhancer. Meat Muscle Biol. 1:122-137. https://doi.org/10.22175/ mmb2017.01.0006.

Sofos, J. N. 1983. Effects of reduced salt $(\mathrm{NaCl})$ levels on sensory and instrumental evaluation of frankfurters. J. Food Sci. 48 (6):1692-1695, 1699. https://doi.org/10.1111/j.1365-2621. 1983.tb05062.x.

Steinhaus, M., and P. Schieberle. 2005. Characterization of odorants causing an atypical aroma in white pepper powder (Piper nigrum L.) based on quantitative measurements and orthonasal breakthrough thresholds. J. Agr. Food Chem. 53:6049-6055. https://doi.org/10.1021/jf0506030.

Steinhaus, P., and P. Schieberle. 2007. Characterization of the key aroma compounds in soy sauce using approaches of molecular sensory science. J. Agr. Food Chem. 55:6262-6269. https:// doi.org/10.1021/jf0709092.

Stevenson, R. J., R. A. Boakes, and J. Prescott. 1998. Changes in odor sweetness resulting from implicit learning of a simultaneous odor-sweetness association: An example of learned synesthesia. Learn. Motiv. 29:113-132. https://doi.org/10. 1006/lmot.1998.0996. 
Stevenson, R. J., R. A. Boakes, and J. P. Wilson. 2000. Counterconditioning following human odor-taste and color-taste learning. Learn. Motiv. 31:114-127. https://doi.org/10. 1006/lmot.1999.1044.

Stevenson, R., J. Prescott, and R. Boakes. 1999. Confusing tastes and smells: How odours can influence the perception of sweet and sour tastes. Chem. Senses. 24:627-635. https://doi.org/ 10.1093/chemse/24.6.627.

Tada, M., I. Shinoda, and H. Okai. 1984. L-ornithyltaurine, a new salty peptide. J. Agr. Food Chem. 32:992-996. https://doi.org/ 10.1021/jf00125a009.

Tamura, M., T. Nakatsuka, M. Tada, Y. Kawasaki, E. Kikuchi, and H. Okai. 1989. The relationship between taste and primary structure of "delicious peptide" (Lys-Gly-Asp-Glu-Glu-SerLeu-Ala) from beef soup. Agric. Biol. Chem. 53:319-325. https://doi.org/10.1080/00021369.1989.10869317.

Tarver, T. 2010. Desalting the food grid. Food Technol.-Chicago. 64:45-50.

U.S. Department of Health and Human Services and USDA. 2015. 2015-2020 Dietary guidelines for Americans. 8th edition. http://health.gov/dietaryguidelines/2015/guidelines/. (Accessed 11 March 2020).

Van Gemert, L. J. 2011. Odour thresholds: Compilations of odour threshold values in air, water and other media. Edition 2011. Oliemans Punter \& Partners BV, Utrecht. p. 1-486.
Wang, J., Y. Z. Li, R. R. Chen, J. Y. Bao, and G. M. Yang. 2007. Comparison of volatiles of banana powder dehydrated by vacuum belt drying, freeze-drying and air-drying. Food Chem. 104:1516-1521. https://doi.org/10.1016/j.foodchem.2007. 02.029 .

Watanabe, A., G. Kamada, M. Imanari, N. Shiba, M. Yonai, and T. Muramoto. 2015. Effect of aging on volatile compounds in cooked beef. Meat Sci. 107:12-19. https://doi.org/10.1016/ j.meatsci.2015.04.004.

Wenther, J. B. 2003. The effect of various protein ingredients utilized as a lean meat replacement in a model emulsion system and frankfurters. PhD diss. Iowa State Univ., Ames, IA. p 325.

WHO. 2016. Salt reduction. https://www.who.int/news-room/factsheets/detail/salt-reduction. (Accessed 12 March 2020).

Xiao, Z., B. Fan, Y. Niu, M. Wu, J. Liu, and S. Ma. 2016. Characterization of odor-active compounds of various chrysanthemum essential oils by gas chromatography-olfactometry, gas chromatography-mass spectrometry and their correlation with sensory attributes. J. Chromatogr. B. 1009:152-162. https://doi.org/10.1016/j.jchromb.2015.12. 029.

Yamasaki, Y., and K. Maekawa. 1978. A peptide with delicious taste. Agr. Biol. Chem. Tokyo. 42:1761-1765. https://doi. org/10.1080/00021369.1978.10863242. 